\title{
Feasibility Study of Using Excess Heat from GTL Process for Seawater Desalination
}

\author{
Jagannath Saiyee Srivatsan ${ }^{1} \&$ Mahmood Amani ${ }^{1}$ \\ ${ }^{1}$ Petroleum Engineering Program, Texas A\&M University at Qatar, Doha, Qatar \\ Correspondence: Mahmood Amani, Petroleum Engineering Program, Texas A\&M University at Qatar, P.O. Box \\ 23874, Doha, Qatar. Tel: 974-4423-0119. E-mail: Amani@tamu.edu
}

Received: May 14, 2012 Accepted: May 20, 2012 Online Published: May 22, 2012

doi:10.5539/eer.v2n1p182 URL: http://dx.doi.org/10.5539/eer.v2n1p182

\begin{abstract}
Over the years, the increasing prices of crude oil and environmental issues have been the major factors for monetizing natural gas to several products such as LNG, NGL and GTL. With over $910 \mathrm{Tcf}$ of natural gas reserves in Qatar (gas-in-place and recoverable resources), there is tremendous capacity for additional GTL plants in Qatar. Out of the global projected GTL production of 1.92 million B/d, Qatar alone already has planned to produce $696,000 \mathrm{~B} / \mathrm{d}$ ( $36 \%$ of total global production). One of the efficient ways of using the exothermic heat from GTL is for desalination. This helps in reducing a large quantity of the fresh fuel to be used as energy input for desalination.

The need for this study is to investigate the availability of exothermic heat from the Gas-To-Liquids (GTL) process to desalinate seawater thereby producing substantial volumes for industrial and/or domestic sectors. This is performed by first designing a schematic base case model of the GTL operation using Aspen Plus. The quantity and quality of heat available from the cooling of the syngas and syncrude streams is used as the energy source for the desalination process. Both thermal desalination and reverse osmosis processes are considered to determine the optimal process for desalination. An integrated GTL-Desalination (GTL-D) process is later designed to compare the output ratio of the GTL-D as opposed to a standalone desalination process.
\end{abstract}

Keywords: desalination, excess heat, gas to liquid plants, syngas

\section{Introduction}

\subsection{Gas to Liquid (GTL) Unists}

The global GTL production projected by the year 2011 is 1.92 million bbl/day and out of this Qatar alone has planned to contribute a liquid production of $696,000 \mathrm{bbl} / \mathrm{day}$ (Chedid et al., 2007), which is around $36 \%$ of the total production. This is seemingly possible due to the abundant reserves (gas-in-place and recoverable) located in the North Field region of Qatar. Currently Oryx GTL (joint venture between Sasol and Qatar Petroleum) produces $34,000 \mathrm{bbl} / \mathrm{day}$ and plans to expand its production capacity of about $130,000 \mathrm{bbl} /$ day in the future. Shell along with Qatar Petroleum commissioned the world's largest integrated GTL project ith a production capacity of 140,000 bbl/day. This shows tremendous potential for the development of more GTL plants in Qatar and a stepping stone in making a transition from conventional crude oil to a cleaner fuel.

The need for water is increasing tremendously every year that it is becoming scarce in so many regions. Usually heat is imported from external sources or burning fuel to produce the energy required for desalination. An integrated desalination system promotes reduced fuel consumption and energy utilization by using the available excess heat from an exothermic process. Integration can be done with several systems like acid manufacturing plants, refineries and any exothermic process. In our study, we focus on integrating gas-to-liquid (GTL) plant with a desalination system by quantifying the excess available heat to generate electric power to run a reverse osmosis system.

\subsection{Process Description}

Gas-to-Liquids (GTL) is a catalytic chemical process which converts natural gas (primarily methane) into liquid fuels. The process consists of several steps:

1) Pretreatment of natural gas to remove impurities: This is the preliminary stage of the process in which 
the methane rich natural gas is treated to remove the impurities like $\mathrm{H}_{2} \mathrm{~S}$ and $\mathrm{CO}_{2}$. The treated natural gas is then sent to the reformer for generation of syngas (synthesis gas).

2) The syngas generation can be carried out either by partial oxidation or by reforming. Partial oxidation (POx) method involves partial combustion of natural gas at sufficiently high temperatures $\left(1200-1300^{\circ} \mathrm{C}\right)$. The stoichiometry of the reaction is maintained to yield syngas with the right proportions. A side reaction also occurs where the feed gas reacts with $\mathrm{CO}_{2}$ to produce more syngas (Adesola et al., 2006)

$$
\begin{aligned}
& \mathrm{CH}_{4}+0.5 \mathrm{O}_{2} \rightarrow \mathrm{CO}+2 \mathrm{H}_{2} \\
& \mathrm{CO}_{2}+\mathrm{CH}_{4} \rightarrow 2 \mathrm{CO}+2 \mathrm{H}_{2}
\end{aligned}
$$

The alternate method to produce syngas is 'reforming'. Currerntly there are two types of reforming widely used in the industry - Steam Methane Reforning (SMR) and Autothermal Reforming (ATR).

The SMR consists of the following two steps:

- Reformation of natural gas: This is the first step of the SMR process where methane reacts with steam at temperatures $750-800^{\circ} \mathrm{C}$ to produce syngas, a mixture of $\mathrm{H}_{2}$ and $\mathrm{CO}$.

$$
\mathrm{CH}_{4}+\mathrm{H}_{2} \mathrm{O} \rightarrow \mathrm{CO}+3 \mathrm{H}_{2}
$$

- Water-gas shift reaction: This is the second step where CO from the reforming stage reacts with steam over a nickel catalyst to form hydrogen and carbon dioxide.

$$
\mathrm{CO}+\mathrm{H}_{2} \mathrm{O} \rightarrow \mathrm{CO}_{2}+\mathrm{H}_{2}
$$

Autothermal Reforming (ATR): This is a combination of SMR and POx where oxygen and steam is treated with natural gas in an autothermal reactor. These reactions are very fast since the exothermic reaction of the POx process can supply the energy for the SMR reaction directly. The reactor operates at a very high temperature of $1200^{\circ} \mathrm{C}$ and pressure of 70 bar.

$$
\begin{aligned}
& \mathrm{CH}_{4}+0.5 \mathrm{O}_{2} \rightarrow \mathrm{CO}+2 \mathrm{H}_{2} \\
& \mathrm{CH}_{4}+\mathrm{H}_{2} \mathrm{O} \rightarrow \mathrm{CO}+3 \mathrm{H}_{2}
\end{aligned}
$$

In modelling the process in Aspen Plus, the autothermal reforming was selected. The advantage of the ATR over the POx is that $\mathrm{H}_{2} / \mathrm{CO}$ ratio is often easily favourable. Since the reaction is autothermal, the heat required for steam reforming is provided within the reator and hence no external heating is required.

3) Fischer-Tropsch conversion to produce hydrocarbons: The Fischer-Tropsch (FT) process is a catalyzed chemical reaction in which syngas from the reforming stage is converted to syncrude in the presence of Iron or Cobalt catalysts. The reactions occur in a FT reactor maintained at a temperature of $230^{\circ} \mathrm{C}$ and pressure less than 20 bar.

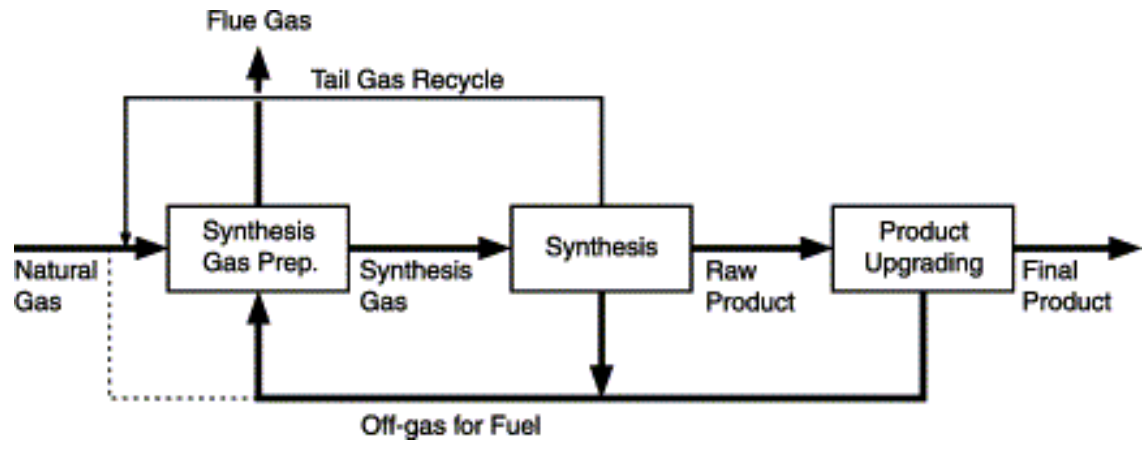

Figure 1. Schematic layout of a Fischer-Tropsch process

Syncrude is a mixture of hydrocarbons with carbon chain length ranging upto 50. The FT reaction is highly exothermic, yielding products like naphtha, diesel and waxes along with water as by-product.

$$
(2 \mathrm{n}+1) \mathrm{H}_{2}+\mathrm{nCO} \rightarrow \mathrm{C}_{\mathrm{n}} \mathrm{H}_{(2 \mathrm{n}+2)}+\mathrm{nH}_{2} \mathrm{O}
$$

The reaction proceeds via chain propogation of $\left(-\mathrm{CH}_{2}-\right)$ groups to yield paraffinic long chain 
hydrocarbons which are later fractioned into a range of products, viz. diesel, naphtha, wax etc. The product yield is characterized by the optimum ratios of syngas $(2: 1), \mathrm{S} / \mathrm{C}$ (steam/carbon) of 0.6 and $\mathrm{O} / \mathrm{C}$ (oxygen/carbon) of 0.5 . These ratios are controlled and maintained for enchanced product yield.

4) Upgrading to produce finished products: Upgrading can produce a wide range of commercial products from gasoline to diesel o candle wax by the process of hydrocracking and hydroisomerisation (Choi et al., 1996). Fuels produced from the FT process are of a high quality since they have low aromaticity and zero sulphur content. The diesel fraction in syncrude has a high cetane number resulting in superior combustion propertied and reduced emissions. This diesel is blended with conventionally used diesel and used as fuel in automobiles. Apart from diesel, other products such as alcohols, naphtha and waxes can be produced by suitable upgrading processes.

\subsection{Problem Statement}

To design a base case model of a GTL process and use the exothermic heat as the energy source for desalination as opposed to using a fresh source of energy. Both thermal and membrane options of desalination were analyzed and compared. The aim was to develop a techno-economic analysis of the process and reduce its cost and enhance its energy efficiency.

The following steps were incorporated:

Aspen Plus to develop the base case GTL model

Perform pinch analysis to assess the heat profile during heat integration

Quantifying the energy requirements for both desalination techniques

Techno-economic evaluation of the GTL process

A PFD of the Integrated GTL-Desalination system with MED and RO techniques are presented below in Figures 2 and 3 .

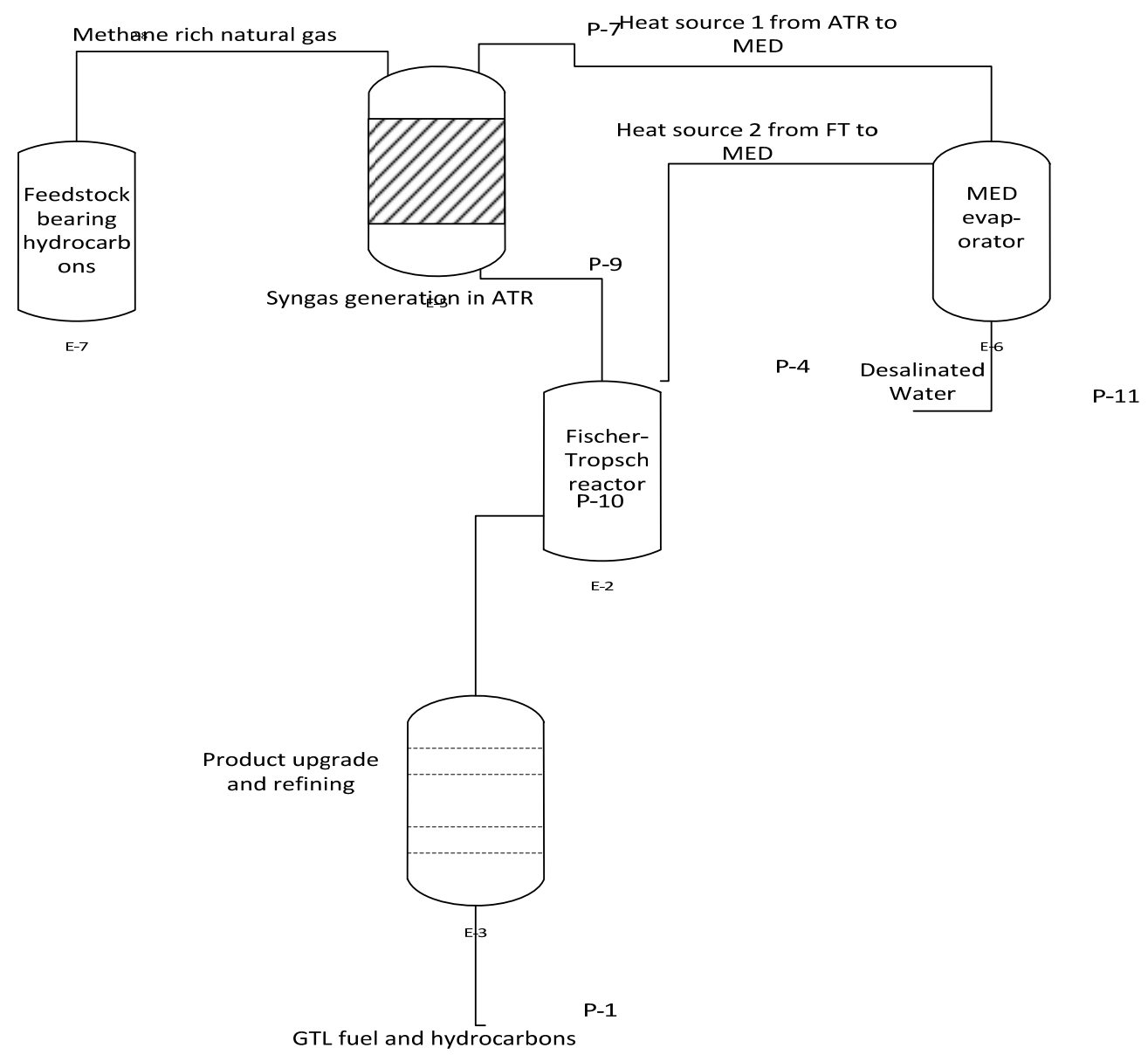

Figure 2. Integrated GTL-MED layout 
Figure 2 represents integrated GTL model using MED desalination techniques where the excess heat produced from the ATR and FT reactor are used to provide energy for the thermal desalination process.

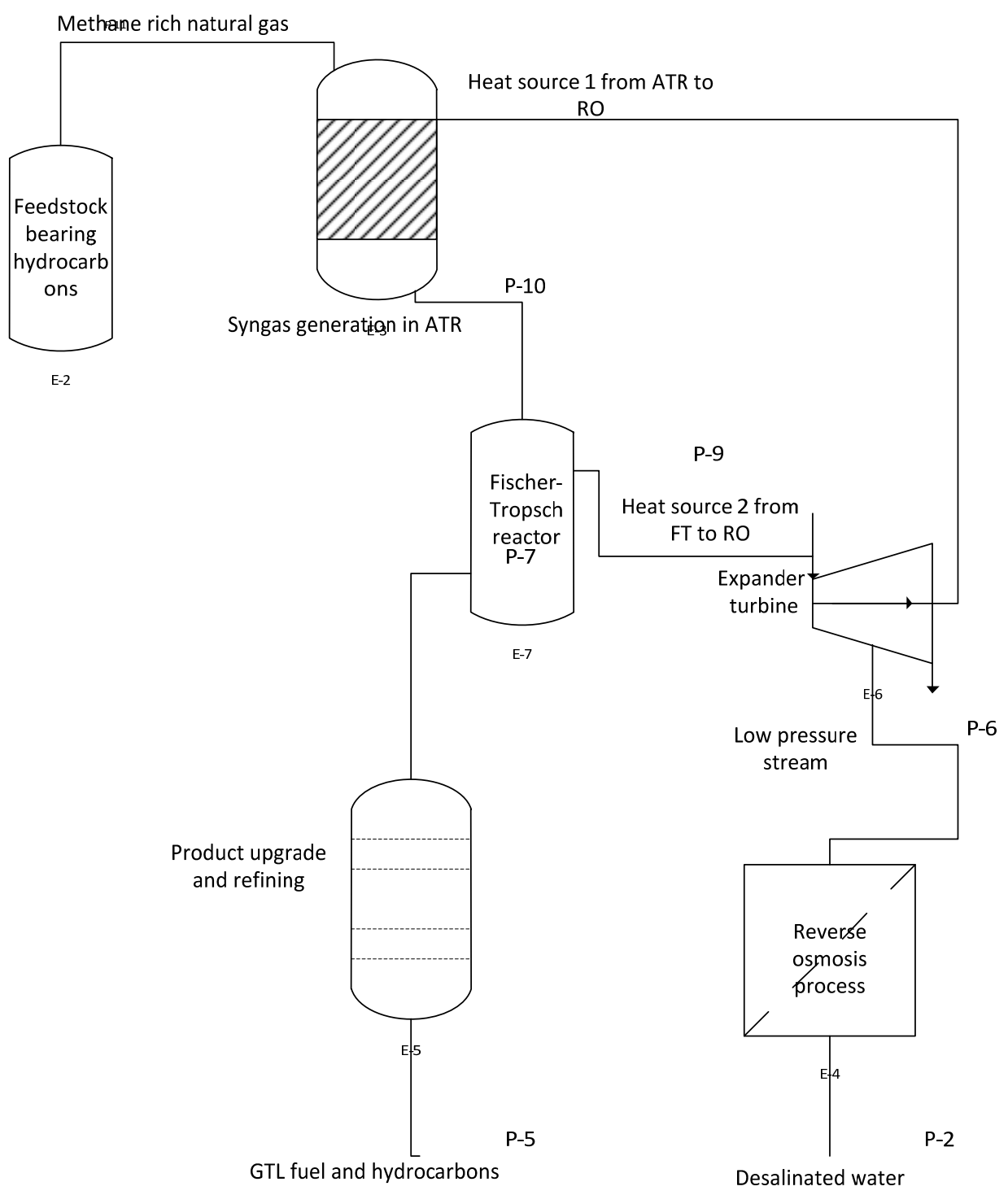

Figure 3. Schematic integrated GTL using RO technique

\section{Process Heat Balance}

In a typical process, there are several hot and cold streams which need to be cooled and heated respectively. For a cost effective process, the best approach is to integrate all the heating and cooling utilities as opposed to using external utilities. Hence the concept of HENs (Heat Exchange Networks) is of paramount importance where the heat between the hot and cold streams can be transferred minimizing the usage of external utilities (El-Halwagi 2006). Figure 4 schematically represents a HEN where the supply and target temperatures of the hot and cold streams are given. 


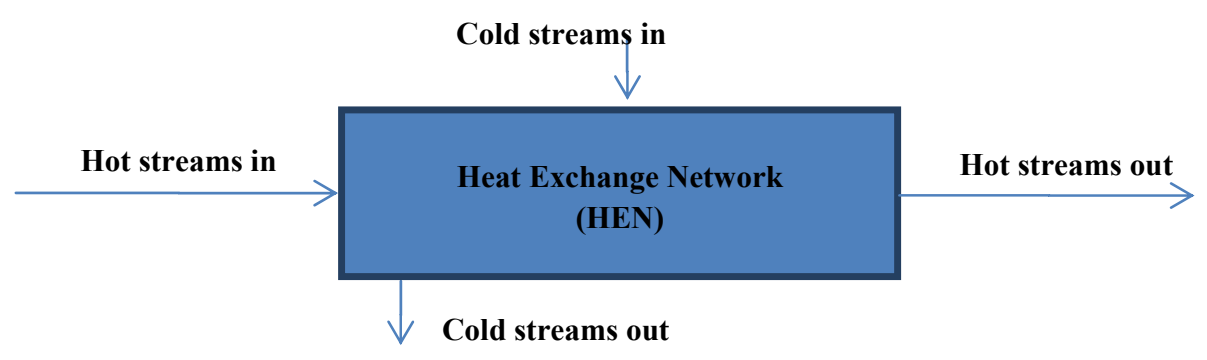

Figure 4. Heat exchange network

\section{GTL Process}

\subsection{Model and Pinch Analysis}

A GTL process model was developed using Aspen Plus. The input streams - NATGAS, $\mathrm{H}_{2} \mathrm{O}$ and $\mathrm{O}_{2}$ flow rates were assumed to adhere to the syngas ratio of 1:2. This simulation was performed to produce $100,000 \mathrm{bpd}$ (barrels per day) of GTL products. In Figure 4, natural gas is first sent to a pre-reformer to remove $\mathrm{H}_{2} \mathrm{~S}$ and other impurities. The treated natural gas, now rich in its methane content along with oxygen is sent to the ATR for manufacture of syngas. This is an autothermal reaction where the exothermic heat from the partial oxidation process provides energy to the steam reforming process. Syngas leaving the reformer is at a temperature of $1200^{\circ} \mathrm{C}$ and 64 bar pressure. This is cooled down using a cooler before entering the Fischer-Tropsch reactor. The reaction conditions inside the reactor are $237^{\circ} \mathrm{C}$ and 18 bar. Syncrude leaving the reactor is cooled again before it is sent for product upgrading.

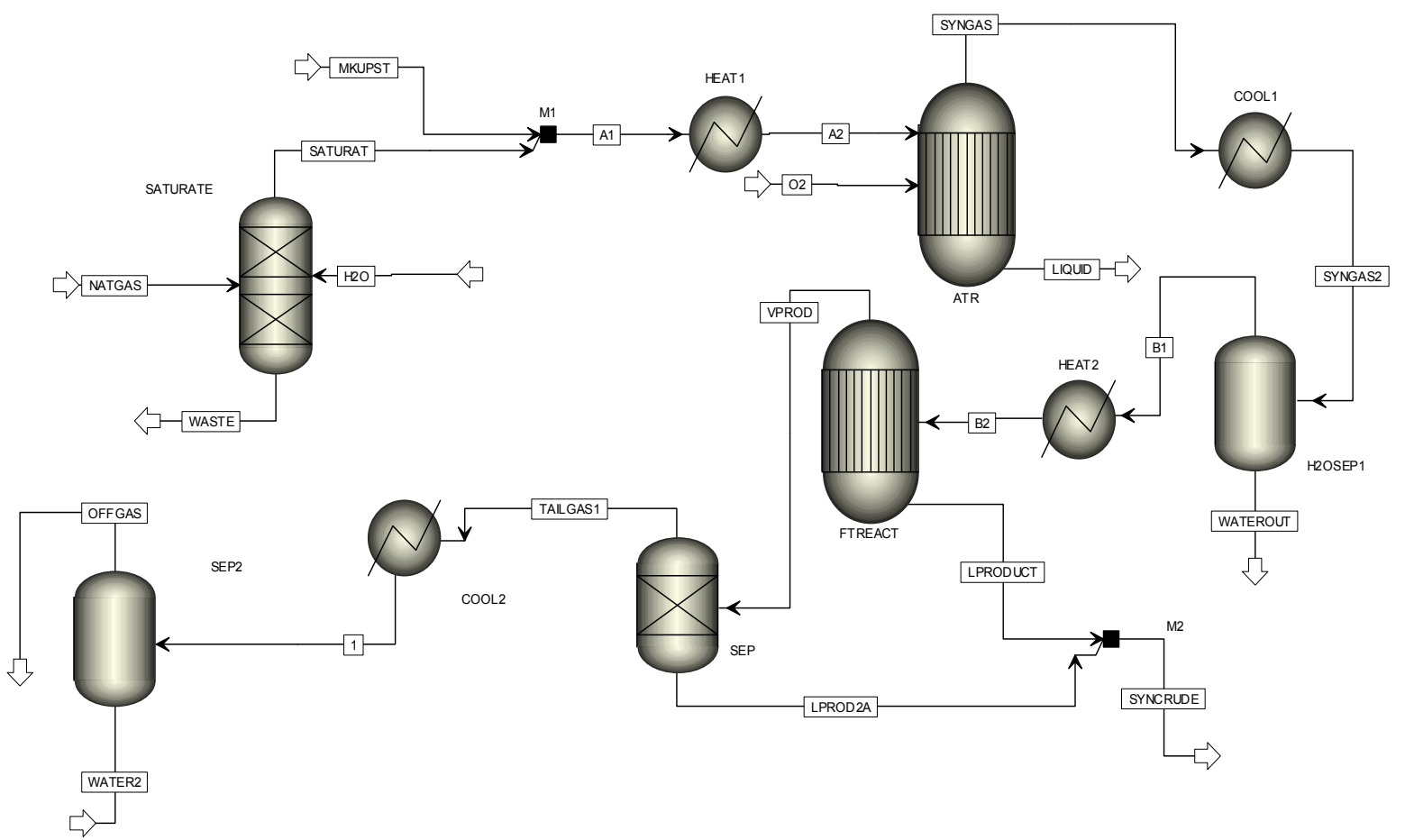

Figure 5. Aspen model of the GTL process

Table 1 shows the feed gas composition for the inlet NATGAS stream.

The flow rate, temperature and pressure of the feed streams are listed below in Table 2 .

Table 3 shows the reaction conditions inside the reformer and the reactor. 
Table 1. Feed gas composition

\begin{tabular}{cc}
\hline Component & Mole \% \\
\hline Methane & 95.39 \\
Ethane & 3.91 \\
Propane & 0.03 \\
Nitrogen & 0.08 \\
Carbon di-oxide & 0.59 \\
\hline
\end{tabular}

Table 2. Composition of feed stream

\begin{tabular}{lccc}
\hline Stream Name & Flowrate $(\mathbf{K g} / \mathbf{H r})$ & Temperature $\left.^{0} \mathbf{c}\right)$ & Pressure(Bar) \\
\hline NATGAS & 896,280 & 40 & 34 \\
$\mathrm{H}_{2} \mathrm{O}$ & $1,195,020$ & 600 & 63 \\
$\mathrm{O}_{2}$ & 990,000 & 260 & 35 \\
\hline
\end{tabular}

Table 3. Block configurations

\begin{tabular}{lll}
\hline Block Name & Temperature $\left(\mathbf{(}^{\mathbf{c})}\right.$ & Pressure (Bar) \\
\hline ATR & 1200 & 64 \\
FTREACT & 237 & 18 \\
\hline
\end{tabular}

The reactions taking place in both the autothermal reformer and the Fischer-Tropsch reactor are highly exothermic. The GTL process is $60 \%$ thermally efficient resulting in $40 \%$ heat loss internally (within the process). The major heat losses are encountered with the syngas stream from the ATR and the vapor stream from the FT reactor due to their exothermic nature. An overall steam balance for the process is performed using Pinch analysis (El-Halwagi, 2006) to quantify the amount of steam that can be used for desalination. Table 4 below lists the heat duties across each heat exchanger.

Table 4. Hot and cold streams for pinch analysis

\begin{tabular}{cc}
\hline Utilities & Enthalpy (Mw) \\
\hline Heat 1 & 540.73 \\
Heat 2 & 540.73 \\
Heat 3 & 22.9 \\
Cool 1 & 2564.72 \\
Cool 2 & 205.84 \\
\hline
\end{tabular}
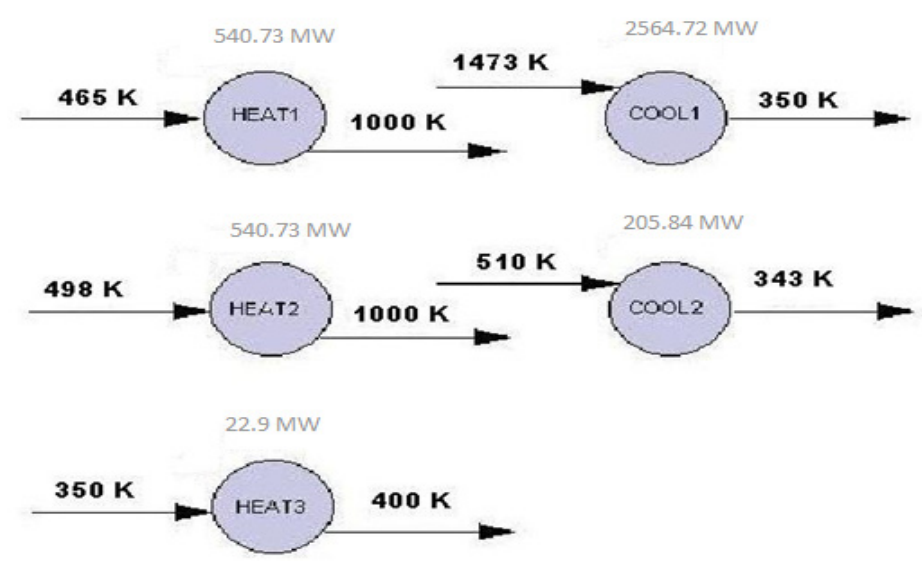

Figure 6. Representation of hot and cold streams 
HEAT 1 represents the heat load between SATURAT and A2 streams (465K to $1000 \mathrm{~K}$ )

HEAT 2 represents the heat load between MKUPST and A2 streams (498K to 1000K)

HEAT 3 represents the heat load between B1 and B2 streams (350K to 400K)

COOL 1 represents the heat load between SYNGAS and SYNGAS2 streams (1473K to 350K)

COOL 2 represents the heat load between TAILGAS1 and 1 streams (510K to $343 \mathrm{~K}$ )

The blocks HEAT and COOL are the heat exchangers across which there is transfer of heat between streams.

The thermal pinch analysis is conducted to determine the amount of potential heat that could be exchanged between the hot and the cold streams. This helps in deciding how much hot and cold utilities are available after before and after heat integration. A cascade diagram was constructed using the heat loads across the heat exchangers. Hence after integration, it was found that no heating utilities were required which indicates the exothermic nature of the GTL process and the cooling utilities available was calculated to be $1667 \mathrm{MW}$. Now, all of this 1667MW cannot be used as some of it is recycled internally. In order to minimize the cost of utilities, it is necessary to screen them which is done by plotting the grand composite curve (GCC). The GCC is constructed directly from the cascade diagram. The GCC helps in demarcating the pressure regions and identifying 'pockets' which are regions that are fully integrated by transferring heat from process hot to process cold streams.

The GCC for the process is show in Figure 7.

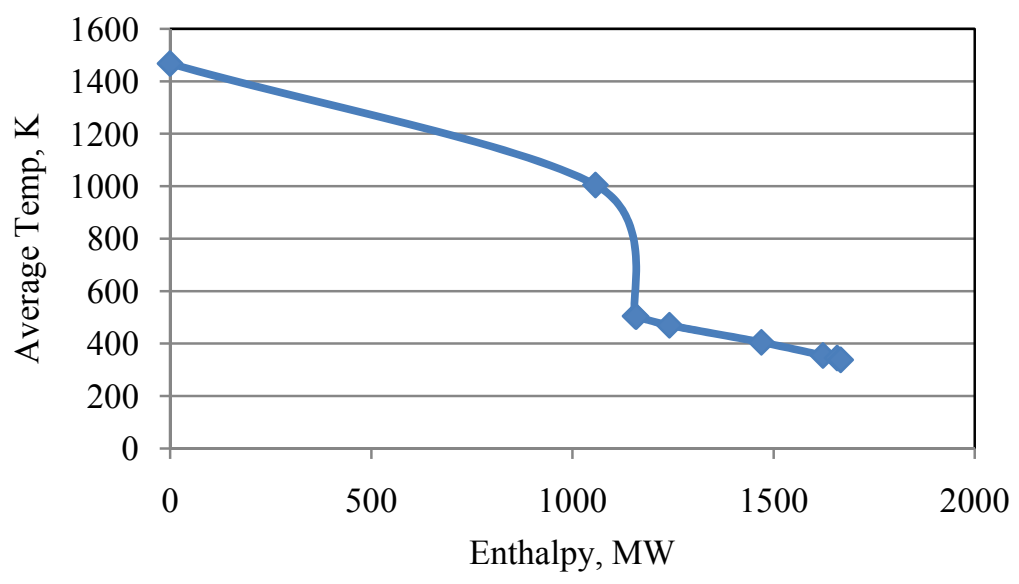

Figure 7. Grand composite curve after heat integration

\subsection{Desalination by Multiple-effect Distillations (MED)}

An innovative vapor-compression desalination system is used by employing the method of dropwise condensation (Lara Ruiz, 2005). The vapor-compression method produces water at satisfactory energy efficiencies. MED has a number of effects (evaporators) that operates at successively lower temperatures. Heat is supplied only to the first effect where seawater enters and is raised to its boiling point producing vapors which is passed to the successive evaporator allowing the condensed steam to be collected at the bottom. The vapors continue to pass through successive evaporators of lower temperatures and pressures until it is collected in the final stage in the condenser the mass and energy balance for the evaporator are given below:

Steam side enthalpy balance is

$$
q_{s}=m_{s}\left(H_{s}-H_{c}\right)=m_{s} h_{f g}
$$

where,

$\mathrm{q}_{\mathrm{s}}=$ rate of heat transfer $(\mathrm{BTU} / \mathrm{hr})$

$\mathrm{H}_{\mathrm{s}}=$ specific enthalpy of steam $(\mathrm{KJ} / \mathrm{kg})$

$\mathrm{H}_{\mathrm{c}}=$ specific enthalpy of condensate $(\mathrm{KJ} / \mathrm{kg})$

$\mathrm{h}_{\mathrm{fg}}=$ latent heat of evaporation $(\mathrm{KJ} / \mathrm{kg})$

$\mathrm{m}_{\mathrm{s}}=$ mass flow rate of steam $(\mathrm{kg} / \mathrm{hr})$ 
Seawater side enthalpy balance is

$$
q=m_{v} H_{v}-m_{f} H_{f}+m_{b} H_{b}=\left(m_{f}-m_{b}\right) H_{v}-m_{f} H_{f}+m_{b} H_{b}
$$

where,

$\mathrm{H}_{\mathrm{v}}=$ specific enthalpy of vapor $(\mathrm{KJ} / \mathrm{kg})$

$\mathrm{H}_{\mathrm{f}}=$ specific enthalpy of feed $(\mathrm{KJ} / \mathrm{kg})$

$\mathrm{H}_{\mathrm{b}}=$ specific enthalpy of exiting brine $(\mathrm{KJ} / \mathrm{kg})$

At steady state,

$$
\begin{gathered}
q_{s}=q \\
m_{s} h_{f g}=\left(m_{f}-m_{b}\right) H_{v}-m_{f} H_{f}+m_{b} H_{b}
\end{gathered}
$$

Since seawater does not have appreciable heat of dilution,

Enthalpy of exiting brine $=0$ (Lara Ruiz 2005)

$$
H_{f}=C_{p f}\left(T_{b}-T_{f}\right)
$$

where,

$\mathrm{C}_{\mathrm{pf}}=$ specific heat of seawater $(\mathrm{KJ} / \mathrm{kg} \mathrm{K})$

$$
m_{s} h_{f g}=\left(m_{f}-m_{b}\right) \lambda-m_{f} C_{p f}\left(T_{b}-T_{f}\right)
$$

where,

$\lambda=$ latent heat of vaporization $(\mathrm{KJ} / \mathrm{kg} \mathrm{K})$

The compressor energy required for this was calculated to be $14.7 \mathrm{MJ} / \mathrm{m}^{3}$ (Lara, 2005) which amounts to $976,481 \mathrm{~m}^{3} /$ day of desalinated water. The steam condensate is recycled to the boiler for its boiler feed water (Khawaji et al., 2007)

\subsection{Desalination by Reverse Osmosis}

In the reverse osmosis process, the water from a liquid of a higher concentration of dissolved solids is forced to flow through the semi-permeable membrane to the low concentration side where this water can be collected. The process is achieved by applying enough pressure to overcome the osmotic pressure forces on a membrane to yiels high quality water. The heart of the RO system is the semi-permeable membrane which acts as a molecular filter to remove up to $99 \%$ of the dissolved solids. The semi-permeable membrane allows water to pass through while it retains the solids (salt molecules). As pressure is applied to the concentrated solution, water is forced through the membrane from the concentrated side to the dilute side, leaving the dissolved solids behind (Mandil et al., 1998).

In the RO process, the energy to produce the required pressure is generated using a turbine where the steam is converted to useful electric load. Steam generated from the GTL enters the turbine. The exhaust from the turbine enters the condenser at atmospheric pressure enabling maximum expansion to deliver maximum work. The energy requirement for the process is calculated as $6.5 \mathrm{KWh} / \mathrm{m}^{3}$. Assuming a recovery of $40 \%$, the quantity of desalinated water was calculated to be $583,392 \mathrm{~m}^{3} /$ day.

The energy requirement for the $\mathrm{RO}$ is calculated using the following:

$$
E R Q U=6.9 \times \frac{P f}{(3600 \times Y \times E p m)}
$$

where ERQU - Pumping energy requirement in $\mathrm{kWh} / \mathrm{m}^{3}$

$\mathrm{P}_{\mathrm{f}}-$ feed pressure in psi, $\mathrm{P}_{\mathrm{f}}=70 \mathrm{bar}=70 * 14.7 \mathrm{psi}$

$\mathrm{Y}$ - recovery (taken as 0.4 here)

$\mathrm{E}_{\mathrm{pm}}$ - combined pump and motor efficiency taken as 0.75 here

\subsection{Process Economics}

The overall process economics is broken down into three sections starting with the base-case GTL economics where assumptions are made pertinent to GTL alone. This is followed by the economics of integrated GTL which is sub-divided into multi-effect desalination (MED) and reverse osmosis (RO). Basic assumptions are again made with respect to water cost for Qatar and capital cost and operating costs as well. 


\subsection{Evaluating Process Economics}

In this study, a GTL plant with a capacity of 100,000 bbl/day has been designed and the economics has been calculated for the same. The entire calculations for calculating the excess heat loads have been performed and the economics has been done for the same.

The economics is calculated by performing the following steps:

1) Developing an annual cash flow analysis for a stand-alone GTL process and for an integrated GTL-desalination process using both thermal (MED) and membrane (RO) desalination techniques.

2) Taking economic assumptions such as;

- Natural gas feed basis is $1 \mathrm{Bcf} /$ day

- Economic plant life is 20 years

- Capital cost amortized over 10-year period

- Straight line depreciation model

- Salvage value is $10 \%$

- Capital is only for year 0 and production starts from year 1

3) Taking process assumptions such as;

- Thermal efficiency of GTL is $10 \%$

- Syncrude composition is $75 \%$ diesel, $20 \%$ naphtha and $5 \%$ LPG

4) Cost assumptions

- Capital cost of GTL is $\$ 25,000 / \mathrm{bbl} / \mathrm{d}$ (World Energy Source, 2009)

- MED plant capital is $\$ 1200 / \mathrm{m}^{3} / \mathrm{d}$ (European Membrane House)

- RO plant capital is $\$ 750 / \mathrm{m}^{3} / \mathrm{d}$ (European Membrane House)

- Operating costs for MED is $\$ 0.16 / \mathrm{m}^{3}$ (Ophir et al., 2006)

- Operating costs for RO is $\$ 0.27 / \mathrm{m}^{3}$ (Ejjeh, 2007)

- Desalinated water cost is $\$ 1.2 / \mathrm{m}^{3}$ (QEWC)

5) Net Present Value (NPV)

6) Payback period (PI)

7) Annual CAPEX, OPEX and revenue

\subsection{Economics of GTL}

An industrial scale GTL plant of capacity 100,000 bbl/day with 1Bcf/day of natural gas feed whose product breakdown is as follows (Adegoke, 2006):

- Diesel $-75 \%$

- Naphtha $-20 \%$

- $\quad \mathrm{LPG}-5 \%$

The capital cost for GTL typically ranges between $\$ 20,000$ - $\$ 30,000 / \mathrm{bbl} /$ day (World Energy Source). However, the Shell GTL plant (Pearl GTL) in Qatar which will be producing 140,000 bbl/day of GTL fuel has reported the total investment for the plant ot be between $\$ 12$ billion and $\$ 18$ billion. This would mean that the capital cost for daily production of GTL fuels will range between $\$ 85,000$ and $\$ 130,000$. Using this as a ballpark, the total capital investment (TCI) for a 100,000 bbl/day productions rate will be $\$ 9.8$ billion. Assuming the fixed capital investment (FCI) to be $85 \%$ of TCI, the fixed capital cost is $\$ 8.33$ billion. The breakdown of GTL expenditure is as follows

- Syngas production $-30 \%$

- Fischer-Tropsch process $-15 \%$

- Product upgrade $-10 \%$

- Utilities $-15 \%$

- Offsites $-20 \%$ 
- Other process units $-10 \%$

Using the unit capital cost, the annual investment cost was calculated to be $\$ 2.5$ billion.

To calculate OPEX, the natural gas heating value was assumed to be 1000BTU/cf.

The following assumptions were made to calculate the OPEX (World Energy Source, 2009):

- Feedstock gas cost - \$1.50/MMBTU

- Non-gas OPEX - $\$ 5 / \mathrm{bbl}$ of product

Based on calculations the net OPEX was found to be $\$ 351$ million/year over the entire 20 year period.

To calculate the price of GTL products, the following prices for diesel, naphtha and LPG were used:

- $\quad$ Diesel - \$77/bbl (World Energy Source, 2009)

- Naphtha - $\$ 71 / \mathrm{bbl}$

- $\quad$ LPG - $\$ 40 /$ bbl (Nymex)

The operating cost is calculated as the sum of the raw materials cost (shown in Table 5) which is calculated based on the selling price of the commodities and the other costs such as labor, maintenance etc. from ASPEN ICARUS.

Table 5. Operating costs for GTL

\begin{tabular}{llll}
\hline Raw materials & Cost of commodity & Flowrate $\mathbf{( k g} / \mathbf{h r})$ & Annual cost $\mathbf{( \$ / y r )}$ \\
\hline Natural gas & $\$ 0.2 / \mathrm{kg}$ & 850,000 & $1,489,200,000$ \\
Water & $\$ 0.21 / \mathrm{ton}$ & $1,300,000$ & $2,391,480$ \\
Oxygen & $\$ 0.2 / \mathrm{kg}$ & $1,150,000$ & $2,014,800,000$ \\
Operating costs & & & $4,906,000$ \\
Total & & & $3,511,297,480$ \\
\hline
\end{tabular}

Table 6. GTL sales

\begin{tabular}{llll}
\hline Products & Production rate (gal/hr) & Selling price $\mathbf{( \$ )}$ & Annual sales $\mathbf{( \$ / y r )}$ \\
\hline Diesel & 131,250 & $\$ 3.06 /$ gal & $3,518,235,000$ \\
LPG & 8,750 & $\$ 1.87 /$ gal & $143,335,500$ \\
Naphtha & 35,000 & $\$ 1.85 / \mathrm{gal}$ & $567,210,000$ \\
Total & & & $4,228,780,500$ \\
\hline
\end{tabular}

Table 7. Annual net cash flow

\begin{tabular}{lc}
\hline \multicolumn{1}{c}{ Items } & Value \\
\hline Plant capacity & 100,000 bbl/day \\
Plant life (years) & 20 \\
Fixed capital investment (FCI) (\$/yr) & 8.33 billion \\
Total capital investment (TCI) (\$/yr) & 9.8 billion \\
Operating costs (\$/yr) & $3,511,297,480$ \\
GTL sales (\$/yr) & $4,228,780,500$ \\
Salvage value $(\$)$ & 0.833 billion \\
Depreciation $(\$ / y r)$ & 0.374 billion \\
Annual net cash flow (profitability, \$) & $\mathbf{3 , 8 8 5 , 2 9 7 , 4 8 0}$
\end{tabular}

- Return on Investment: This is calculated as the ratio of profits to total capital investment on a percentage basis.

$$
\mathrm{ROI}=(4,228,780,500-3,885,297,480) / 9,800,000,000 * 100=3.5 \%
$$


- Payback period: This is the ratio of fixed capital investment over the annual net cash flow.

Payback period $=8,330,000,000 /(4,228,780,500-3,885,297,480)=24$ years

\subsection{Economics of MED}

Similar to the economics of GTL, and with assumptions stated previously, economics for the MED which delivers $976,481 \mathrm{~m}^{3} /$ day has also been calculated. Unit capital costs for MED has been assumed with unit operating costs per cubic meter of desalinated water.

- Depreciation costs are assumed to be over a 20 year period.

- Discount rate is $10 \%$

- Capital cost is $\$ 1200 / \mathrm{m}^{3} /$ day

- CAPEX is taken only at year zero and assumed to kick production from year 1

- Operating costs MED is taken to be $\$ 0.16 / \mathrm{m}^{3}$.

- Cost of water is $\$ 1.20 / \mathrm{m}^{3}$

For unit capital cost of $\$ 1200 / \mathrm{m}^{3} /$ day the investment cost was found to be $\$ 1.17$ billion.

Annual operating cost over the 20 year period was found to be $\$ 57.02$ million/year.

Depreciation is $\$ 0.05$ billion/year.

Net revenue was calculated to be $\$ 427.7$ million/year.

Total annualized cost (TAC) is the difference of revenue and the sum of OPEX and depreciation.

$\mathrm{TAC}=$ revenue $-(\mathrm{OPEX}+$ depreciation $)=\$ 0.32$ billion $/$ year.

\subsection{Economics of Reverse Osmosis}

Similar to the economics of MED, economics for the RO which desalinates $583,392 \mathrm{~m}^{3} /$ day has also been calculated. Unit capital costs for RO have been assumed with unit operating costs per cubic meter of desalinated water.

- Depreciation costs are assumed to be over a 20 year period.

- Discount rate is $10 \%$

- Capital cost is $\$ 750 / \mathrm{m}^{3} /$ day

- Cost of water is $\$ 1.20 / \mathrm{m}^{3}$

- CAPEX is taken only at year zero and assumed to kick production from year 1

- Operating costs MED is taken to be $\$ 0.27 / \mathrm{m}^{3}$ and it is higher than for MED although it has a lower capital cost. More operating personnel are required for RO thus increasing the labor costs. Membrane has to be replaced periodically and this adds to the maintenance cost. After performing the after-tax cash flow analysis, the following were calculated:

For unit capital cost of $\$ 750 / \mathrm{m}^{3} /$ day the investment cost was found to be $\$ 0.43$ billion approx.

Annual operating cost over the 20 year period was found to be $\$ 57.5$ million/year.

Net revenue was calculated to be $\$ 256$ million/year.

Depreciation is $\$ 19$ million/year.

$\mathrm{TAC}=$ revenue $-(\mathrm{OPEX}+$ depreciation $)=\$ 0.18$ billion $/$ year.

\subsection{Economics of Integrated GTL-Desalination}

The final economics study is for the integrated GTL-desalination. Although this is not a complete step-by-step process in design, the economics is calculated for the complete industrial scale level process. Assumptions similar to GTL and desalination are assumed with capital cost taken as the sum of the two capital costs; and economics for the integrated process has also been calculated. Depreciation costs are assumed to be over a 20 year period.

- Discount rate is $10 \%$

- Total investment cost is $\$ 10.97$ billion for MED and \$10.23 billion for RO

- CAPEX is taken only at year zero and assumed to kick production from year 1 
- Operating costs MED is taken to be $\$ 0.16 / \mathrm{m}^{3}$ although the capital cost is lesser.

- Water cost is $\$ 1.20$ per $^{3}$

More operating personnel are required for RO thus increasing the labor costs. Membrane has to be replaced periodically and this adds to the maintenance cost. After performing the after-tax cash flow analysis, the following were calculated as shown in Table 8.

Table 8. Comparative economic analysis

\begin{tabular}{llll}
\hline Process parameters & GTL & GTL-MED & GTL-RO \\
\hline CAPEX & \$9.80 billion & \$10.97 billion & \$10.23 billion \\
Annual OPEX & \$3.51 billion & \$4.0 billion & \$4.1 billion \\
Annual revenue & \$4.2 billion & \$4.64 billion & \$4.4 billion \\
Payback period & 24 years & 21.6 years & 22.09 years \\
\hline
\end{tabular}

We see that there is not much difference between the economics in the above three cases. This is possibly because of the low water price in the region that favors the installation of the system to be cheaper. But in terms of net revenue, there are no significant higher returns as compared to the stand-alone GTL system. This is an area of interest that could possibly create more interest in future research in terms of the economic approach. If we can device a method to build the GTL system at a lower cost (bulk of the cost is attributed towards the ATR and FT-reactor), this can become much more promising and as a viable option in catering to the needs of the domestic and industrial sector.

\section{Conclusion}

Qatar has a growing potential in terms of being the energy capital of the world. Its vast resources can help in utilizing the natural gas to set up GTL plants and also help in meeting the country's water demands. The auto-thermal reforming technique and the Fischer-Tropsch are promising techniques which can help in developing the process. Advancement in these two technologies mainly in terms of cost reduction will help in better GTL economics thus able to make GTL as a fuel by itself. Desalination techniques have been developing over the years. The most recent dropwise condensation method of heat transfer delivers high results in terms of water that can be desalinated. Energy requirements for both processes help in determining the quantity of water that can be desalinated. The pinch point analysis helps in achieving maximum heat exchange and in determining the amount of heating and cooling utilities. Economics was calculated for all systems and there was no significant difference in terms of revenue. As expected the integrated system requires a higher OPEX and CAPEX when compared to the base case GTL system. Adding desalination to the GTL system did not elevate the costs so much, hence it can be considered a feasible option, Depending on the price of water and other regional parameters, the costs for the integrated system could vary.

In conclusion, gas-to-liquids technology offers excellent prospects to countries with gas resources. GTL has proven to be an attractive alternative to crude oil with substantial benefits in terms of social and environmental development. The fuel shows tremendous compatibility with vehicles in terms of emissions, making it an environmentally better fuel as opposed to the conventional diesel. This gives options to decide if we want to maximize GTL production by recirculating the natural gas back into the system or to maximize electricity/water production. The possibility of using GTL as a fuel by itself and not by blending with conventional diesel is feasible only if the price of crude oil stays high.

\section{Acknowledgement}

The authors would like to express their appreciation for the valuable guidance provided by Dr. Patrick Linke, Dr. Christine Ehlig-Economides and Dr. Mahmoud El-Halwagi.

\section{References}

Adegoke, A. A., Barrufet, M., \& Ehlig-Economides, C. (2006). Integrated GTL Power-Generation Technology: The Optimal Solution to Natural Gas Exploitation in Nigeria. SPE 105966.

Chedid, R., Kobrosly, M., \& Ghajar, R. (2007). The potential of gas-to-liquid technology in the energy market: The case of Qatar. Energy Policy, 35(10), 4799-4811. http://dx.doi.org/10.1016/j.enpol.2007.03.017 
Choi, G. N., Kramer, S. J., Tam, S. T., \& Fox, J. M. (1996). Gas to Liquids Chemlink Australasia, 1992. Spring National Meeting, American Institute of Chemical Engineers, Houston. Retrieved from http://www.chemlink.com.au/gtl.htm

El-Halwagi, M. M. (2006). Process Integration, process systems engineering.

Lara Ruiz, J. H. J. (2005). An advanced vapor-compression desalination system. PhD Dissertation, Texas A\&M University.

Mandil, M. A., Farag, H. A., Naim, H. A., \& Attia, M. K. (1998). Feed salinity and cost-effectiveness of energy recovery in reverse osmosis desalination. Journal of Desalination, 120(1-2), 89-94. http://dx.doi.org/10.1016/S0011-9164(98)00205-7

Michael, J. Economides. (2005). The Economics of Gas to Liquids Compared to Liquefied Natural Gas. World Energy, 8(1), 136-140. 